Report Detailing Comparative Analysis of Results from High Flux Isotope Reactor and National Institute of Standards and Technology Small-Angle Neutron Scattering Experiments

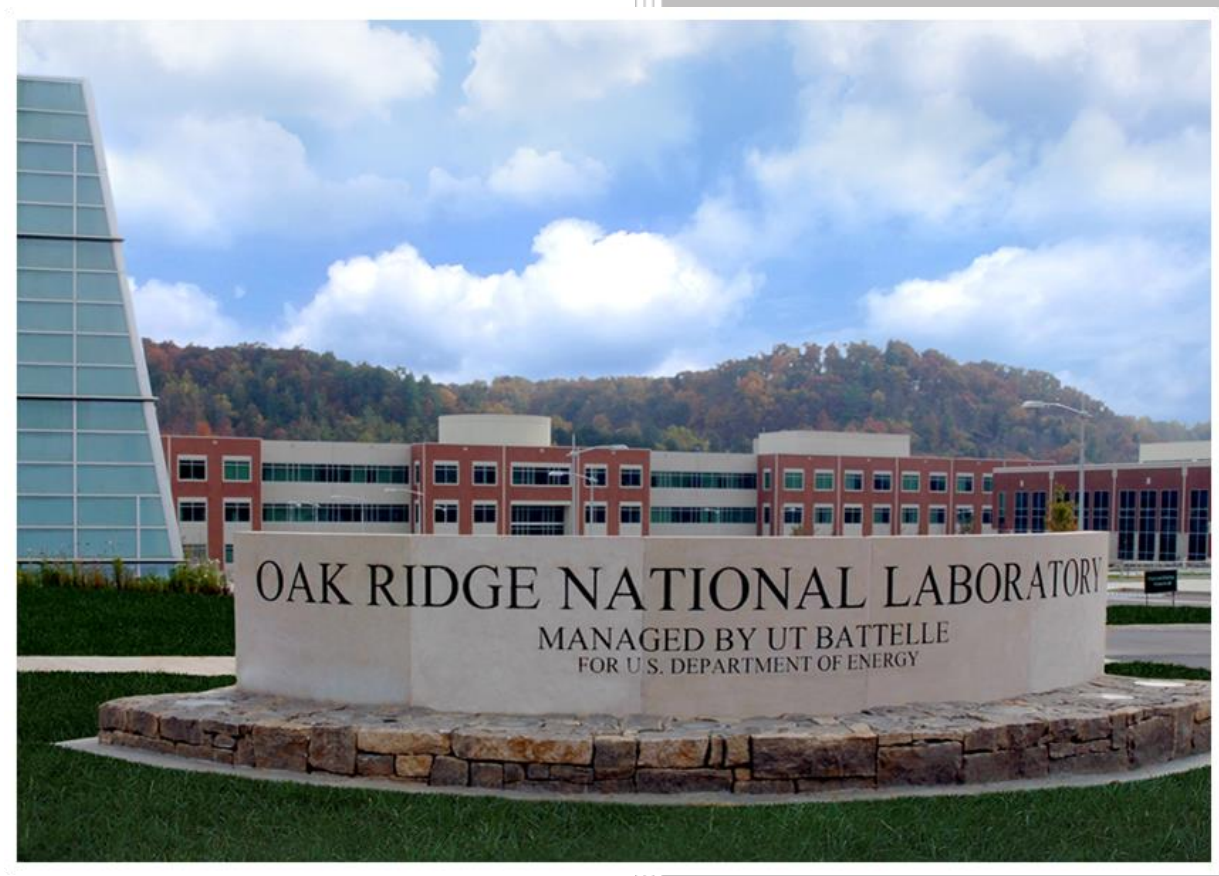

M.A. Sokolov ${ }^{1}$, K.C. Littrell' 1 , P. Wells ${ }^{2}$, and N.J. Cunningham ${ }^{2}$ ${ }^{1}$ Materials Science and Technology Division, Oak Ridge National Laboratory 2University of California Santa Barbara

September 2015 


\section{DOCUMENT AVAILABILITY}

Reports produced after January 1, 1996, are generally available free via US Department of Energy (DOE) SciTech Connect.

Website http://www.osti.gov/scitech/

Reports produced before January 1,1996, may be purchased by members of the public from the following source:

National Technical Information Service

5285 Port Royal Road

Springfield, VA 22161

Telephone 703-605-6000 (1-800-553-6847)

TDD 703-487-4639

Fax 703-605-6900

E-mailinfo@ntis.gov

Website http://www.ntis.gov/help/ordermethods.aspx

Reports are available to DOE employees, DOE contractors, Energy Technology Data Exchange representatives, and International Nuclear Information System representatives from the following source:

Office of Scientific and Technical Information

PO Box 62

Oak Ridge, TN 37831

Telephone 865-576-8401

Fax 865-576-5728

E-mail reports@osti.gov

Website http://www.osti.gov/contact.html

This report was prepared as an account of work sponsored by an agency of the United States Government. Neither the United States Government nor any agency thereof, nor any of their employees, makes any warranty, express or implied, or assumes any legal liability or responsibility for the accuracy, completeness, or usefulness of any information, apparatus, product, or process disclosed, or represents that its use would not infringe privately owned rights. Reference herein to any specific commercial product, process, or service by trade name, trademark, manufacturer, or otherwise, does not necessarily constitute or imply its endorsement, recommendation, or favoring by the United States Government or any agency thereof. The views and opinions of authors expressed herein do not necessarily state or reflect those of the United States Government or any agency thereof. 
This page intentionally left blank 
Light Water Reactor Sustainability

\title{
REPORT DETAILING COMPARATIVE ANALYSIS OF RESULTS FROM HIGH FLUX ISOTOPE REACTOR AND NATIONAL INSTITUTE OF STANDARDS AND TECHNOLOGY SMALL-ANGLE NEUTRON SCATTERING EXPERIMENTS
}

\author{
M.A Sokolov ${ }^{1}$, K.C. Littrell ${ }^{1}$, P.Wells ${ }^{2}$, and N.J. Cunningham ${ }^{2}$ \\ ${ }^{1}$ Materials Science and Technology Division, Oak Ridge National Laboratory \\ ${ }^{2}$ University of California Santa Barbara
}

Date Published: September 2015

Prepared under the direction of the

U.S. Department of Energy

Office of Nuclear Energy

Light Water Reactor Sustainability

Materials Aging and Degradation Pathway

Prepared by

OAK RIDGE NATIONAL LABORATORY

Oak Ridge, TN 37831-6283

managed by

UT-BATTELLE, LLC

for the

US DEPARTMENT OF ENERGY

under contract DE-AC05-00OR22725 
This page intentionally left blank 


\section{CONTENTS}

LIST OF FIGURES .


This page intentionally left blank 


\section{LIST OF FIGURES}

\section{Figure}

1 Alternative method for determination of the $\mathrm{M} / \mathrm{N}[15]$......

2 Scattering curves for both HFIR and NIST data for: Left: Nuclear scattering and Right: Nuclear + Magnetic; Top: VD un-aged and Bottom: VD aged $350^{\circ} \mathrm{C}, 11000 \mathrm{~h}$.

3 Scattering curves for both NIST and scaled HFIR data for: Left: Nuclear scattering and Right: Nuclear + Magnetic scattering curves; Top: VD un-aged and Bottom: VD aged $350^{\circ} \mathrm{C}, 11000 \mathrm{~h} \ldots \ldots .7$

4 Scattering curves for both NIST and scaled HFIR data for: Left: Nuclear scattering and Right: Nuclear + Magnetic scattering curves; Top: VH un-aged and Bottom: $\mathrm{VH}$ aged $350^{\circ} \mathrm{C}, 11000 \mathrm{~h} . \ldots \ldots . .8$

$5 \quad$ Nuclear scattering curves at both, NIST and HIFR, for aged VD, left, and VH, right, alloys with $0^{\circ} \pm 15^{\circ}$ sector average. 
This page intentionally left blank 
ORNL/TM-2015/423

\section{LIST OF TABLES}

\section{Table}

Page

$1 \quad$ Chemical composition of two model alloys characterized in this study......................... 2 2 Summary of fitting results for $\mathrm{VD}$ and $\mathrm{VH}$ aged alloys with $0^{\circ} \pm 15^{\circ}$ sector average nuclear scattering

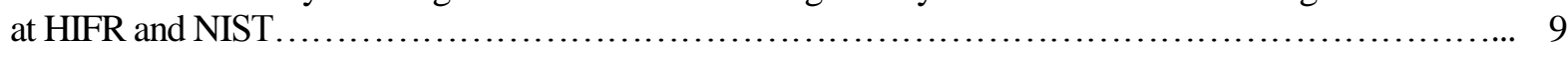


This page intentionally left blank 
This research was sponsored by the U.S. Department of Energy, Office of Nuclear Energy, for the Light Water Reactor Sustainability Research and Development effort. The authors extend their appreciation to Dr. Jeremy Busby for programmatic support and to Dr. Randy Nanstad for technical review. Special thanks are to Prof. Robert Odette for detailed discussions of these results and his continuous encouragements of SANS studies on RPV steels in general. 
This page intentionally left blank 
ORNL/TM-2015/423

\section{INTRODUCTION}

The major issues regarding irradiation effects are discussed in [1-3] and have also been discussed in previous progress and milestone reports. As noted previously, of the many significant issues discussed, the issue considered to have the most impact on the current regulatory process is that associated with effects of neutron irradiation on RPV steels at high fluence, for long irradiation times, and as affected by neutron flux. It is clear that embrittlement of RPV steels is a critical issue that may limit LWR plant life extension. The primary objective of the LWRSP RPV task is to develop robust predictions of transition temperature shifts (TTS) at high fluence $(\varphi \mathrm{t})$ to at least $10^{20} \mathrm{n} / \mathrm{cm}^{2}(>1 \mathrm{MeV})$ pertinent to plant operation of some pressurized water reactors (PWR) for 80 full power years. Correlations between the high flux test reactor results and low flux surveillance specimens must be established for proper RPV embrittlement predictions of the current nuclear power fleet. Additionally, a complete understanding of defect evolution for high nickel RPV steels is needed to characterize the embrittlement potential of Mn-Ni-enriched precipitates (MNPs), particularly for the high fluence regime. While understanding of copper-enriched precipitates (CRPs) have been fully developed, the recent discovery and experimental verification [4] of 'late blooming' MNPs with little to no copper for nucleation has stimulated research efforts to understand the evolution of these phases. New and existing databases will be combined to support developing physically based models of TTS for high fluence-low flux $\left(\varphi<10^{11} \mathrm{n} / \mathrm{cm}^{2}-\mathrm{s}\right)$ conditions, beyond the existing surveillance database, to neutron fluences of at least $1 \times 10^{20} \mathrm{n} / \mathrm{cm}^{2}(>1 \mathrm{MeV})$. Moreover, a large number of various RPV materials have been irradiated in the ATR-2 experiment and will be jointly studied by University of California Santa Barbara (UCSB) and ORNL to address the majority of microstructural characteristics discussed above, see Ref. [5] and [6] for details. UCSB has performed a large number of SANS experiments in the past at the National Institute of Standards and Technology (NIST) Center for Neutron Research (NCNR). These data are taken from RPV steels irradiated in a wide range of flux-fluence space and will be very useful in comparing to the upcoming UCSB ATR-2 irradiation characterization since most of the SANS experiments with ATR-2 materials will be performed at the ORNL High Flux Isotope Reactor (HFIR). However in the previous report [7], some discrepancies were observed between HFIR and NCNR generated data. One of the hypotheses was that there was some kind of extra scattering occurring off the sample holders that results in the HFIR curves falling above the NCNR curves. To test this hypothesis, UCSB provided thermally aged samples that have been previously run at NCNR to ORNL for testing at HFIR while ORNL performed some improvements to the experimental set up at HFIR.

This report provides the status for the Level 3 Milestone (M3LW-15OR0402013), "Complete report detailing comparative analysis of results from High Flux Isotope Reactor and National Institute of Standards and Technology small-angle neutron scattering experiments." This milestone is associated with small-angle neutron scattering characterization at the High Flux Isotope Reactor of various model alloys that had been previously characterized at NCNR by UCSB.

\section{DESCRIPTIONS OF MATERIALS}

An $\mathrm{Fe}-\mathrm{Cu}$ binary alloy, $\mathrm{VH}$, and an $\mathrm{Fe}-\mathrm{Cu}-\mathrm{Mn}$ ternary model alloy, VD, that had previously been aged were examined. The compositions are in Table 1 below. The alloys were normalized at $775^{\circ} \mathrm{C}$ for 17 hrs, salt quenched to $450^{\circ} \mathrm{C}$ and held for 3 minutes than air cooled. The materials were aged at $350^{\circ} \mathrm{C}$ for $11000 \mathrm{hrs}$. 
Table 1. Chemical composition of two model alloys characterized in this study

\begin{tabular}{|c|c|c|c|c|c|}
\hline Alloy & $\mathrm{Cu}$ (wt. \%) & Mn (wt. \%) & $\mathrm{C}$ (wt.\%) & Ti (wt. \%) & $\mathrm{N}$ (ppm) \\
\hline VD & 0.88 & 1.03 & 0.00 & 0.00 & 10 \\
\hline VH & 0.91 & 0.01 & 0.01 & 0.01 & 20 \\
\hline
\end{tabular}

\section{BRIEF DESCIPTION OF SANS DATA COLLECTION AND REDUCTION}

SANS provides microstructural characterization of nanometer- sized irradiation-induced precipitates that may be inaccessible through common characterization techniques, such as electron microscopy. Common irradiation-induced defects in RPV steels scatter neutrons by both nuclear and magnetic contrasts between the scattering feature and the iron matrix. The assumed non-magnetic nature of CRPs and MNPs (for which validity of this assumption has not been determined) provides the basis for SANS analysis of feature dimensions and composition. A detailed description of SANS in RPV steel application is provided in the most recent progress reports [8,9] and in the literature [10].

As previously explained, SANS measurements on the same samples were taken at both HFIR and NCNR. The raw detector count data was reduced to two irradiation-induced feature scattering crosssections (magnetic+nuclear and nuclear) by subtracting background radiation, parasitic scattering, and scattering from an unirradiated control [11].

The data collected at HFIR were taken at the GP SANS instrument in CG2 in a saturated magnetic field of 2 Tesla oriented in the vertical direction at a source-sample distance of $7.082 \mathrm{~m}$ and two sampletarget distances of 8.045 and $1.345 \mathrm{~m}$. Prior to these measurements, the pole pieces and magnetic returnfield were extended by $5 \mathrm{~cm}$ in the vertical direction with soft magnetic iron shims to move the top magnet coil further from the beam center, preventing shadowing of the detector in the vertical direction in the close configuration. Furthermore, additional shielding was placed in front of the collimator box to reduce aperture-external parasitic neutron background at high Q. The sample holders and pole face separations used were the same as in the previous measurements at HFIR CG2. The absolute scattering cross section $\mathrm{d} \Sigma / \mathrm{d} \Omega$ (q) was determined for the longer sample-target geometry by normalization of the attenuated direct beam. The shorter HFIR geometry experiment lacked corresponding transmission data, requiring linear scaling of the scattering cross-section to match the longer geometry absolute scattering cross-section for the over-lapping q-range. The same scale factor was used for all samples. The scaling method for the shorter geometry has been identified as an opportunity for improvement in the future experiments.

The SANS measurements at the NCNR in Gaithersburg, MD were performed on the NG7 beam line, using a neutron wavelength of $\lambda=0.5 \pm 0.03 \mathrm{~nm}$ with a two-dimensional $3 \mathrm{He}$ detector located $1.55 \mathrm{~m}$ from the sample and offset by $\approx 20 \mathrm{~cm}$ to increase the useful scattering vector range. Measurements were made with an $\approx 8 \mathrm{~mm}$ diameter aperture on $\approx 2 \mathrm{~mm}$ thick coupons in a $1.6 \pm 0.1$ T horizontal magnetic field applied along the extrusion direction to saturate the ferromagnetic matrix.

\section{BRIEF DESCRIPTIONS OF SANS DATA ANALYSIS}

Following is an overview of the SANS data analysis, with a more detailed description found elsewhere [12-15]. Analysis of the reduced scattering cross sections data allows for the measurement of the average size (d), number density $(\mathrm{N})$, and volume fraction (f) of the CRPs and MNPs. The magnetic field permits separation of the nuclear (n) and magnetic (m) differential scattering cross sections 
$(\mathrm{d} \Sigma(\mathrm{q}) / \mathrm{d} \Omega)$, where the latter depends on the angle from the horizontal (NCNR) magnetic field direction, $\phi$ as

$$
\frac{d}{d}(q, \quad)=\frac{d}{d}(q)_{n}+\sin ^{2} \frac{d}{d}(q)_{m}
$$

The SANS analysis involves subtracting a measured control $\mathrm{d} \Sigma / \mathrm{d} \Omega$ from that for the sample to isolate the scattering by the precipitates. In this case the control was an un-aged baseline VD and VH alloy with no nucleated precipitates. For the NIST data the 2-D $\mathrm{d} \Sigma(\mathrm{q}) / \mathrm{d} \Omega$ feature data is sector averaged to create 1-D scattering vs. $q$ curves for three angles $(\varphi): 0^{\circ} \pm 30^{\circ}, 45^{\circ} \pm 15^{\circ}$, and $80^{\circ} \pm 10$. An angle of $80^{\circ}$ was used instead of $90^{\circ}$ since the detector is offset from center to increase q. The HFIR data were sector averaged at $0^{\circ} \pm 15^{\circ}$ and $90^{\circ} \pm 15^{\circ}$. The $\mathrm{d} \Sigma / \mathrm{d} \Omega$ is related to the scattering feature size distribution [N(r')], number density $(\mathrm{N})$, volume fraction (f) and scattering contrast factor, $\Delta \rho$; the latter is the difference between the feature and matrix scattering length densities. For a distribution of precipitate sizes the scattering cross section is represented by

$$
\frac{d}{d}(q)=\frac{N_{P}}{N} \quad 2 \int_{r} a(r) V_{P}^{2}(r) F(q r) d r
$$

where $a(r)$ is the fraction of precipitates within dr and we define

$$
a(r) d r=1
$$

It is computationally convenient to have a discrete form of the distribution with average radii, $r_{i} \pm \Delta r$, giving

$$
A\left(r_{i}\right)=\int_{r_{i}}^{r_{i}+r} a(r) d r
$$

For this work a lognormal precipitate size distribution was assumed to represent the aged alloy, and the lognormal probability density function is

$$
f_{p d f}(r ; \mu, \quad)=\frac{1}{r \sqrt{ }} \exp \left\{\frac{(\ln r \mu)^{2}}{2}\right\}
$$

Here $\beta$ is the distribution width parameter, and is equal to the square root of two times the standard deviation of the normally distributed random variable $\ln (\mathrm{r})$. The symbol $\mu$ is the mean of the normally distributed random variable $\ln (\mathrm{r})$. Integrating the lognormal probability density function from 0 to $\mathrm{r}$ results in the cumulative distribution function, which is used to create the discrete, normalized lognormal distribution

$$
A\left(X_{i}\right)=\frac{1}{2}\left(\operatorname{erf}\left(X_{i}\right) \quad \operatorname{erf}\left(X_{i 1}\right)\right)
$$

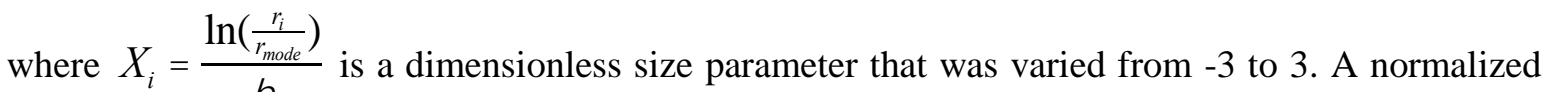
(dimensionless) scattering function, $\mathrm{d} \Sigma^{\prime}(\mathrm{q}) / \mathrm{d} \Omega$, is found by applying the scattering distribution, $\mathrm{A}(\mathrm{r})$, and $\mathrm{d} \Sigma / \mathrm{d} \Omega(\mathrm{q})$ to give

$$
\frac{d^{\prime}(q)}{d}=\frac{{ }_{i} A\left(r_{i}\right) r_{i}^{6} F\left(q, r_{i}\right)}{A\left(r_{i}\right) r_{i}^{6}}
$$


This function represents the shape of the scattering cross section for the lognormal particle size distribution described by $\mathrm{A}(\mathrm{r})$ with $\mathrm{d} \Sigma^{\prime}(0) / \mathrm{d} \Omega$ defined as equal to 1 . The shape of the scattering curve is dependent on the size distribution of the NFs while the number density, $N$, and volume fraction, $f_{v}$, is dependent on the magnitude. The reduced and sector averaged $\left(0^{\circ}, 45^{\circ}, 80^{\circ}\right) \mathrm{d} \Sigma(\mathrm{q}) / \mathrm{d} \Omega f$ data are least square fit in terms of $r_{\text {mode }}, d \Sigma(0) / d \Omega n, \beta$, and $M / N$ using

$$
\frac{d \Sigma(q, \phi)}{d \Omega}=\frac{d \Sigma ?(q)}{d \Omega} \times \frac{d \Sigma(0)_{n}}{d \Omega} \times\left(1+\frac{M}{N} \sin ^{2} \phi\right)
$$

Here, $\mathrm{d} \Sigma(0) / \mathrm{d} \Omega_{\mathrm{n}}$ is the nuclear scattering component at $\mathrm{q}=0$ while the term $\left(1+\mathrm{M} / \mathrm{N} \sin ^{2} \varphi\right)$ scales the data to account for the different amounts of magnetic scattering. The fit parameters are related to the average radius $(<r>)$, number density $(\mathrm{N})$, and volume fraction $\left(\mathrm{f}_{\mathrm{v}}\right)$ of the features by

$$
\begin{aligned}
& <r>=r_{\text {mode }} \exp \left(0.75^{2}\right) \\
& N=(3 / 4)^{2}\left\{\frac{\exp \left(9^{2}\right)}{r_{\text {mode }}^{6}}\right\} \frac{d(0)}{d} \\
& f_{v}=(3 / 4)\left\{\frac{\exp \left(6.75^{2}\right)}{r_{\text {mode }}^{3}{ }^{2}}\right\} \frac{d(0)}{d}
\end{aligned}
$$

However, since the exact composition and atom volume in the precipitates, hence the nuclear scattering contrast, $\Delta \rho_{\mathrm{n}}$, are unknown, $\mathrm{d} \Sigma(\mathrm{q}) / \mathrm{d} \Omega_{\mathrm{n}}$ cannot be used to analyze the SANS data. Assuming that the CRPs and MNPs are non-magnetic and act as magnetic holes in a magnetically saturated ferromagnetic matrix makes the $\Delta \rho_{\mathrm{m}}=\rho$ (matrix) $)_{\mathrm{m}}$, where the $\rho$ (matrix) $)_{\mathrm{m}}$ is known (calculated or measured) for a specified alloy composition.

Instead of least squares fitting, the $\mathrm{M} / \mathrm{N}$ can alternatively be estimated by the fitted slope of $\mathrm{d} \Sigma(\mathrm{q}, \varphi) / \mathrm{d} \Omega$ averaged over a $\mathrm{q}$ range of $\approx 0.8$ to $0.18 \mathrm{~nm}^{-1}$ and plotted versus $\sin ^{2}(\varphi \pm \Delta \varphi)$. Around 8 to 10 $\varphi \pm \Delta \varphi$ values are typically chosen with a $\Delta \varphi$ of $5^{\circ}$. The procedure is illustrated in Figure 1. 


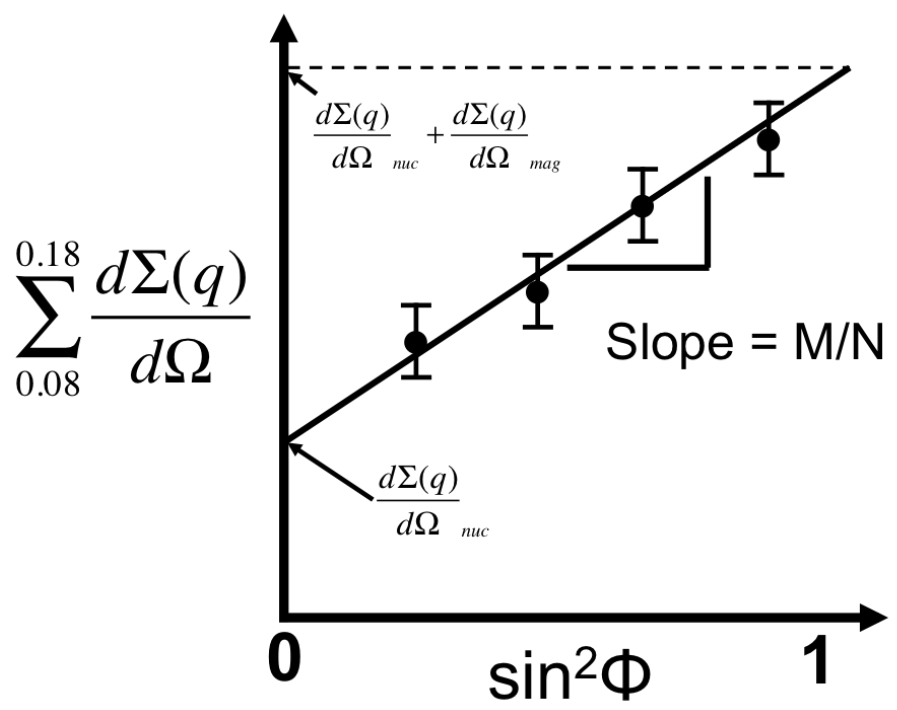

Figure 1. Alternative method for determination of the $M / N$ [15].

Previous analysis of NIST SANS data used specialized IGOR Pro® code. Since the HFIR data are in a different format it was deemed easier to re-write the fitting function using Matlab than reformatting the HFIR data. To do this as quickly and simply as possible the fitting only used the magnetic scattering and did not simultaneously fit all three sector averaged angles $\left(0^{\circ}, 45^{\circ}\right.$, and $\left.80^{\circ}\right)$. The regression analysis was repeated in a similar fashion for the NIST data. For this reason the M/N was not found through fitting three data curves. Since the HFIR data were only given as $\mathrm{M}+\mathrm{N}$ and $\mathrm{N}$ sector averaged data it was not possible to use the alternative method for calculating $\mathrm{M} / \mathrm{N}$ from Figure 1 . Instead the $\mathrm{M} / \mathrm{N}$ was estimated by simply taking the average $\mathrm{d} \Sigma / \mathrm{d} \Omega_{\text {mag }} / \mathrm{d} \Sigma / \mathrm{d} \Omega_{\text {nuc }}$ over the q range of $0.08 \AA-1$ to $0.18 \AA-1$.

\section{SANS RESULTS AND DISCUSSION}

The scattering curves obtained from both NCNR and HFIR for alloys VD and VH were compared to verify that both SANS instruments and setup behaved similarly. Figure 2 compares the data received from HFIR with NIST data for the VD alloy. For all cases the HFIR data were offset along the y-axis. It was realized that the cause for this is the use of a $1 \mathrm{~mm}$ sample thickness at HFIR when the samples are closer to $2 \mathrm{~mm}$. The VH sample scattering curves behaved similarly. 

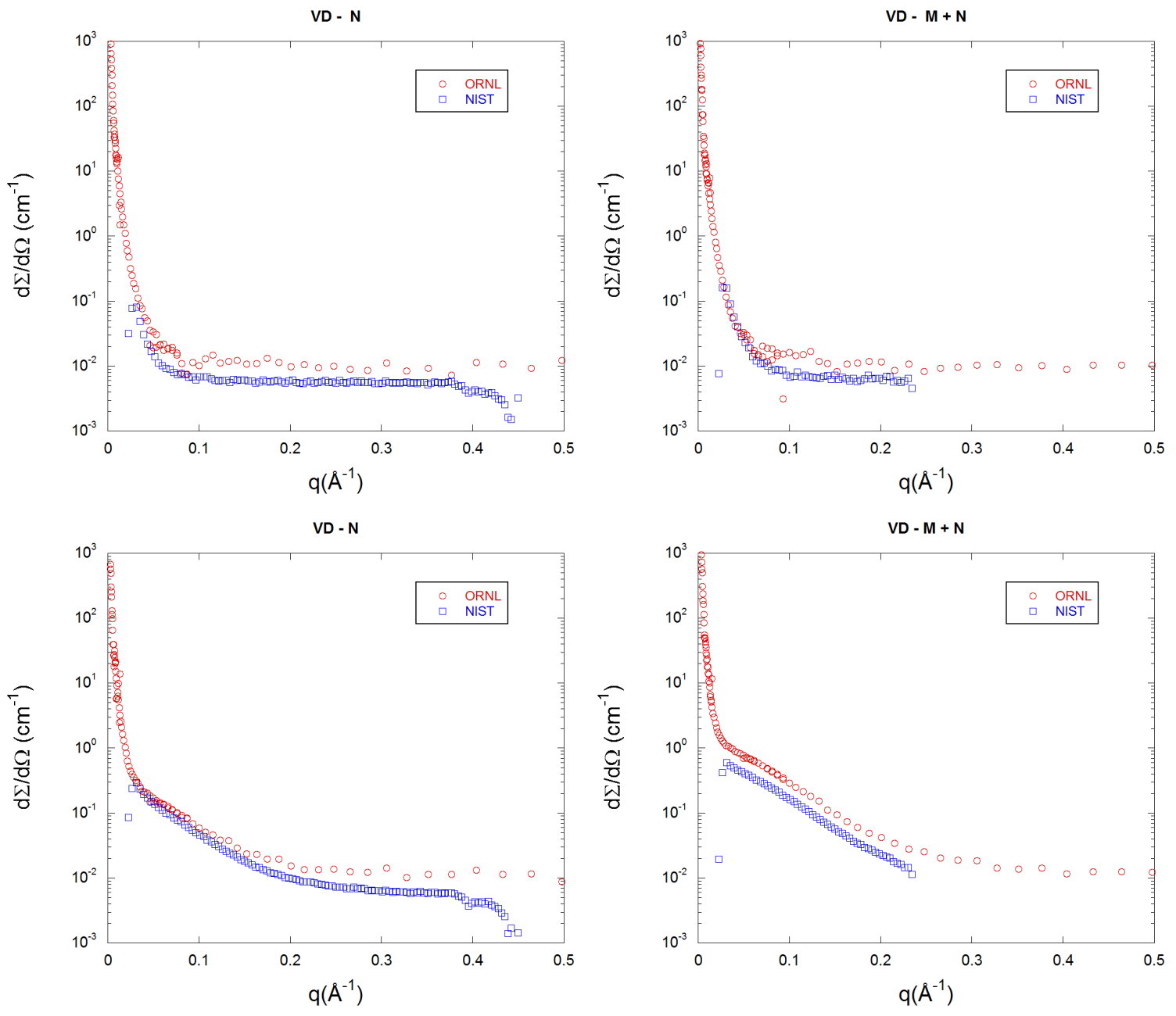

Figure 2. Scattering curves for both HFIR and NIST data for:

\section{Left: Nuclear scattering and Right: Nuclear + Magnetic \\ Top: VD un-aged and Bottom: VD aged $350^{\circ} \mathrm{C}, 11000 \mathrm{~h}$.}

To correct for the sample thickness from $1 \mathrm{~mm}$ to $2 \mathrm{~mm}$, the HFIR data were scaled by one-half. Figure 3 shows the corrected, scaled VD data. The nuclear scattering of the un-aged VD was nearly identical between NIST and HFIR. The magnetic + nuclear scattering exhibited similar incoherent scattering, but differences in scattering were observed at lower q. The opposite was true for the aged VD sample where the nuclear + magnetic scattering curves matched, but the HFIR data showed less nuclear scattering at low q. The incoherent scattering for all VD scaled data matched well between NIST and HFIR. 
ORNL/TM-2015/423
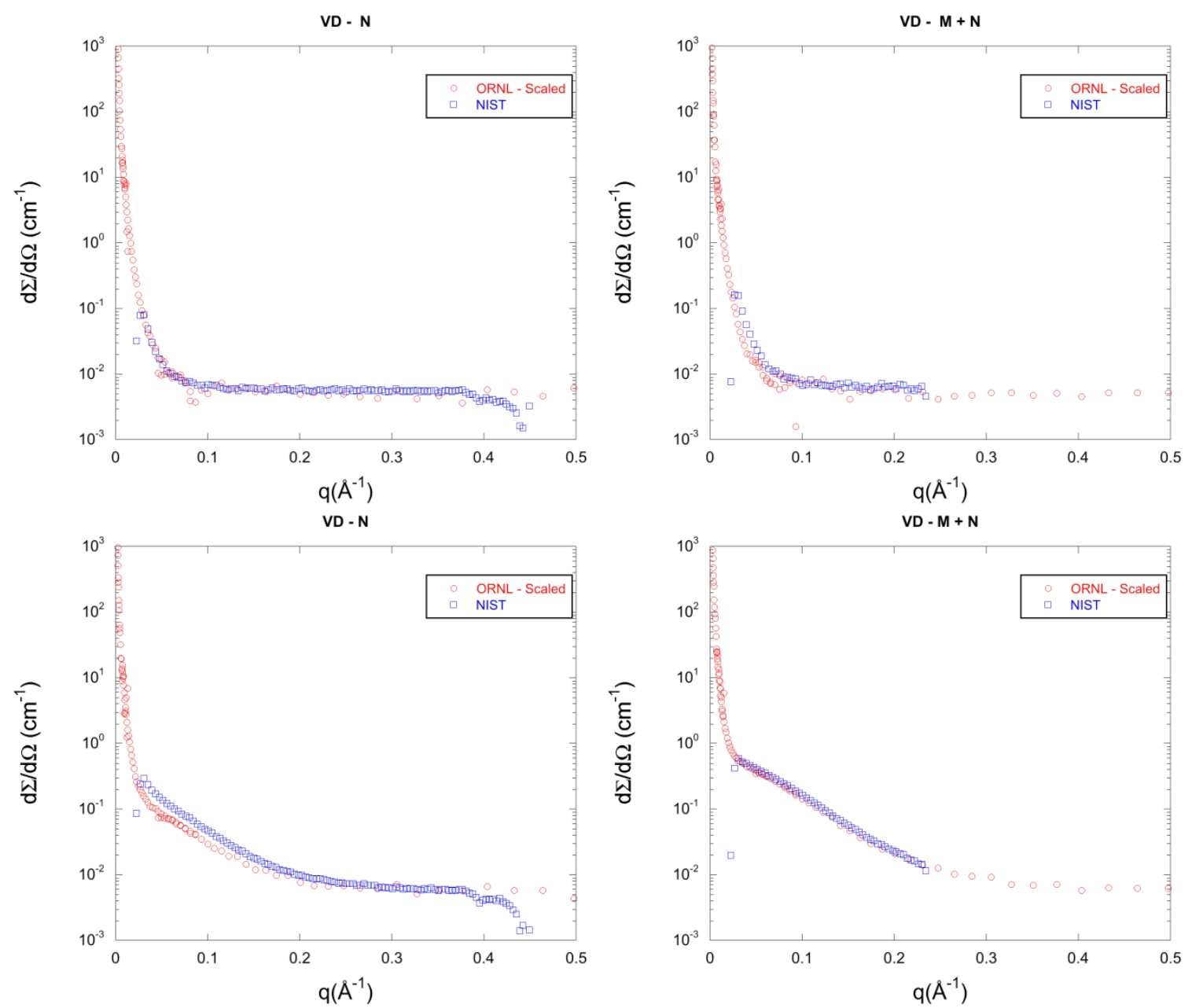

Figure 3. Scattering curves for both NIST and scaled HFIR data for:

Left: Nuclear scattering and Right: Nuclear + Magnetic scattering curves

Top: VD un-aged and Bottom: VD aged $350^{\circ} \mathrm{C}, 11000 \mathrm{~h}$.

The VH alloy data comparison was similar to the VD alloy, see Figure 4. 

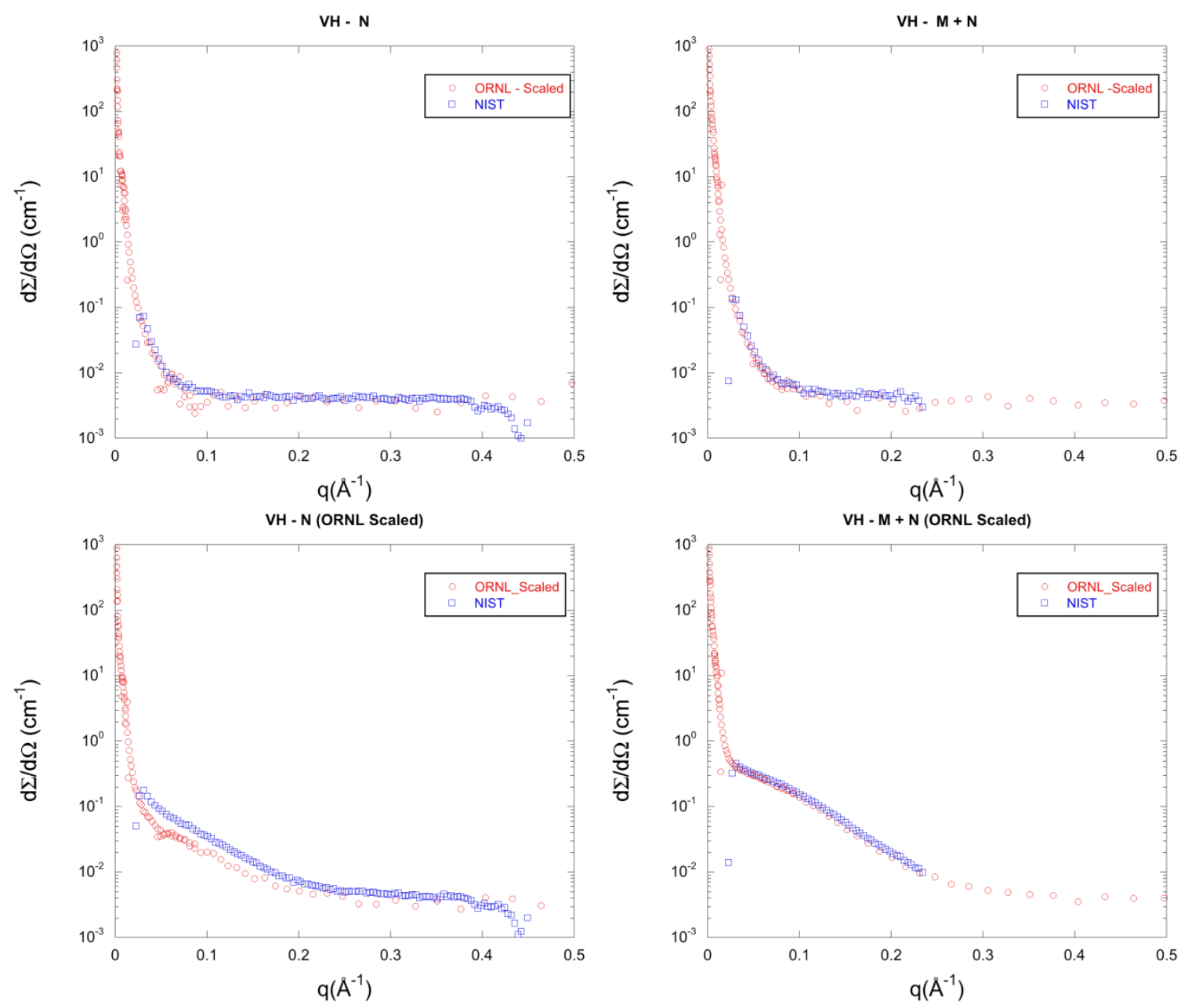

Figure 4. Scattering curves for both NIST and scaled HFIR data for:

\section{Left: Nuclear scattering and Right: Nuclear + Magnetic scattering for}

Top: VH un-aged and Bottom: VH aged $350^{\circ} \mathrm{C}, 11000 \mathrm{~h}$.

One possible cause for the HFIR lower nuclear scattering in both VD and VH aged samples was identified as a difference in how the 2-D detector data were sector averaged. The NIST data used a sector average of $0^{\circ} \pm 30^{\circ}$ while the HFIR data used $0^{\circ} \pm 15^{\circ}$. Thus, NIST data were re-calculated using the same sector averaging, $0^{\circ} \pm 15^{\circ}$, as the HFIR data for both aged, VD and VH alloys, see Figure 5 . 

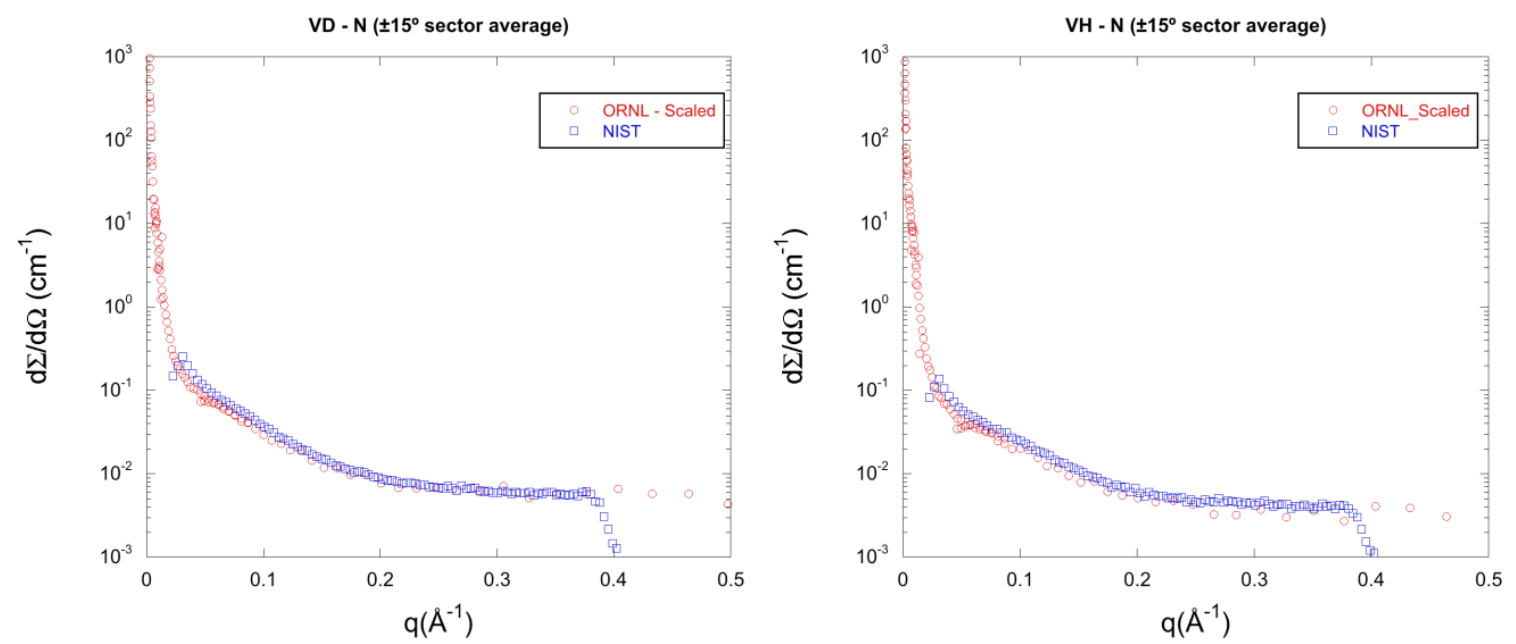

Figure 5. Nuclear scattering curves at both, NIST and HFIR, for aged VD, left, and VH, right, alloys with $0^{\circ} \pm 15^{\circ}$ sector average.

For both VD and VH alloys the un-aged baseline samples were subtracted from the aged sample data to isolate scattering from the features. The nuclear scattering was then subtracted from the magnetic + nuclear to isolate the magnetic component, which was used for the final fit. From the fit parameters the $<\mathrm{r}\rangle, \mathrm{N}$, and $\mathrm{f}$ were calculated and are shown in Table 2. It was found that the NIST and HFIR data give nearly identical results when fitting the magnetic scattering.

Table 2. Summary of fitting results for $\mathrm{VD}$ and $\mathrm{VH}$ aged alloys with $0^{\circ} \pm 15^{\circ}$ sector average nuclear scattering at HIFR and NIST.

\begin{tabular}{|c|c|c|c|c|}
\hline \multirow{2}{*}{} & \multicolumn{2}{|c|}{ VD aged $350^{\circ} \mathrm{C}$} & \multicolumn{2}{c|}{ VH aged $350^{\circ} \mathrm{C}$} \\
\cline { 2 - 5 } & HFIR & NIST & HFIR & NIST \\
\hline$<\mathrm{R}>(\mathrm{nm})$ & 1.36 & 1.37 & 1.53 & 3.51 \\
\hline $\mathrm{N}\left(10^{17} \mathrm{~cm}^{-3}\right)$ & 4.2 & 4.6 & 2.8 & 0.3 \\
\hline $\mathrm{f}_{\mathrm{V}}(\%)$ & 0.44 & 0.49 & 0.42 & 6.9 \\
\hline $\mathrm{M} / \mathrm{N}$ & 4.6 & 4.3 & 7.3 & \\
\hline
\end{tabular}

\section{SUMMARY AND CONCLUSIONS}

Two model alloys in un-aged and aged at $350^{\circ} \mathrm{C}$ for $11000 \mathrm{~h}$ that have been previously measured at NIST were used in this study to compare results of small angle neutron scattering at HFIR and NIST. This comparison was essential since most of the upcoming UCSB ATR-2 irradiation characterization will be performed at ORNL High Flux Isotope Reactor (HFIR). On the other hand, UCSB has performed a large number of SANS experiments in the past at the National Institute of Standards and Technology (NIST) Center for Neutron Research (NCNR). These data were taken from RPV steels irradiated in a wide range of flux-fluence space and, thus, making such comparison an important step in preparing for ATP-2 experiment characterization. Current results showed that all SANS derived microstructural parameters, namely average radius, number density, volume fraction, and magnetic-to-nuclear ratio, are almost identical from NIST and HFIR results.

Based on this comparison, a research plan will be developed to perform SANS measurements of RVP alloys irradiated in the ATR-2 experiment. 


\section{REFERENCES}

1. Eason, E. D., Odette, G. R., Nanstad, R. K., and T. Yamamoto, "A Physically Based Correlation of Irradiation-Induced Transition Temperature Shifts for RPV Steels," ORNL/TM-2006/530, Oak Ridge National Laboratory, February 2007.

2. Nanstad, R. K. and Odette, G. R., "Reactor Pressure Vessel Issues for the Light-Water Reactor Sustainability Program," Proceedings of Env. Deg. Conf., 2009.

3. Odette, G. R. and Nanstad, R. K., "Predictive Reactor Pressure Vessel Steel Irradiation Embrittlement Models: Issues and Opportunities,” J. Metals, 61, 7, July 2009.

4. Miller, M.K. and Russell, K.F., "Embrittlement of RPV steels: An atom probe tomography perspective," J. of Nucl. Matls, 371 (1-3) (2007), p. 145

5. Nanstad, R. K. and Odette G. R., "Reactor Pressure Vessel Task of Light Water Reactor Sustainability Program: Milestone Report on Materials and Machining of Specimens for the ATR-2 Experiment," ORNL/LTR-2011/413, Oak Ridge National Laboratory, January 2011.

6. Nanstad, R. K., Odette, G. R., Yamamoto, T., and Sokolov, M.A., "Postirradiation Examination Plan for ORNL and University of California Santa Barbara Assessment of UCSB ATR-2 Irradiation Experiment," ORNL/LTR2013/598, Oak Ridge National Laboratory, December 2014.

7. Sokolov, M.A., Nanstad, R. K., Miller, M. K., Littrell, K.C., Odette G. R., Wells, P., Sprouster, D. J., and Ecker, L. E. "Comprehensive and Comparative Analysis of Atom Probe, SmallAngle Neutron Scattering, and Other Microstructural Experiments on Available High Fluence Reactor Pressure Vessel Steels," ORNL/LTR-2014/241, Oak Ridge National Laboratory, June 2014.

8. Sokolov, M. A., Littrell, K. C., and Nanstad, R. K., "Reactor Pressure Vessel Task of Light Water Reactor Sustainability Program: Milestone M3LW-13OR042012, Report on Small-Angle Neutron Scattering Experiments of Irradiated RPV Materials," ORNL/TM-2012/630, Oak Ridge National Laboratory, December 2012.

9. Nanstad, R. K., Sokolov, M. A., Miller, M. K., Williams, G.T., and Littrell, K. C., "Microstructural Examinations of Reactor Pressure Vessel Surveillance and Test Reactor Irradiated Materials," ORNL/TM-2013/462, Oak Ridge National Laboratory, September 2013.

10. Sokolov, M.A., Spooner, S., Odette, G.R., Wirth, B.D., and Lucas, G.E., "SANS Study of High-Copper RPV Welds in Irradiated and Annealed Conditions," pp. 333-345 in Effects of Radiation on Materials: 18th International Symposium, ASTM STP 1325, R.K. Nanstad, M.L. Hamilton, F.A. Garner, and A.S. Kumar, Eds., 1999. 
11. Glade, S.C., Wirth, B.D., Odette, G.R, and Kumar,P.A., " Positron annihilation spectroscopy and small angle neutron scattering characterization of nanostructural features in highnickel model reactor pressure vessel steels," J. of Nucl. Materls, 351 (13) (2006) p.197

12. Alinger, M.J., September 2004, On the Formation and Stability of Nanometer Scale Precipitates in Ferritic Alloys during Processing and High Temperature Service, Ph.D. Dissertation, University of California Santa Barbara

13. Alinger, M.J., Odette, G.R., and Hoelzer, D.T., "On the role of alloy composition and processing parameters in nanocluster formation and dispersion strengthening in nanostructured ferritic alloys", Acta Materialia, 57, 2009, 392-406.

14. Cunningham, N.J. September 2012, Study of the Structure, Composition, and Stability of Y-Ti-O nm-Scale Features in Nano-Structured Ferritic Alloys, Ph.D. Dissertation, University of California Santa Barbara.

15. Mader, E., August 1995, Kinetics of Irradiation Embrittlement and Post-Irradiation Annealing of Nuclear Reactor Pressure Vessel Steels, Ph.D. Dissertation, University of California, Santa Barbara. 


\section{INTERNAL \\ DISTRIBUTION}

Busby, J.T.

Chen, X.

Field, K. G.

Leonard, K.J.

Pape, Y. M.

Littrell, K. C.

Nanstad, R.K.

Naus, D.J.

Rosseel, T.M.

Sokolov, M.A.

Williams Jr, D.L. busbyjt@ornl.gov

chenx@ornl.gov

fieldkg@ornl.gov

leonardk@ornl.gov Le

lepapeym@ornl.gov

littrellkc@ornl.gov

nanstadrk@ornl.gov

nausdj@ornl.gov

rosseeltm@ornl.gov

sokolovm@ornl.gov

williamsdljr@ornl.gov

\section{EXTERNAL DISTRIBUTION}

K. McCarthy, Idaho National Laboratory, P.O. Box 1625, Idaho Falls, ID 834153860, (Kathryn.Mccarthy@inl.gov)

R. Reister, GTN Bldg, 1000 Independence Ave, S.W. Washington, DC 20585 ,

(Richard.Reister@nuclear.energy.gov)

G. R. Odette, University of California Santa Barbara, Mech. Engr. Dept., Santa Barbara, CA 931065070

(Odette@engineering.ucsb.edu)

P. Wells, University of California Santa Barbara, Materials Dept., Santa Barbara, CA 93106-5050 (well7765@gmail.com)

N. Cunningham, University of California Santa Barbara, Chem. Engr. Dept, Santa Barbara, CA 93106-5080

(njc@engineering.ucsb.edu) 